Brazilian Journal

of Chemical

ISSN 0104-6632

Printed in Brazil

Engineering

www.scielo.br/bjce

Vol. 35, No. 03, pp. 1117-1128, July - September, 2018

dx.doi.org/10.1590/0104-6632.20180353s20170160

\title{
C-PHYCOCYANIN PURIFICATION: MULTIPLE PROCESSES FOR DIFFERENT APPLICATIONS
}

\author{
Felipe da Silva Figueira ${ }^{1,3}$, Caroline Costa Moraes $^{2}$ and Susana Juliano Kalil ${ }^{1, *}$ \\ ${ }^{1}$ Federal University of Rio Grande, Chemistry and Food School, P.O. Box 474, \\ Rio Grande, RS, Brazil. \\ ${ }^{2}$ Federal University of Pampa, Food Engineering, Bagé, RS, Brazil. \\ ${ }^{3}$ Federal University of West Bahia, Biotechnology Engineering, \\ Luis Eduardo Magalhães, Brazil.
}

(Submitted: March 22, 2017; Revised: November 16, 2017; Accepted: November 17, 2017)

\begin{abstract}
C-phycocyanin is a potential nutraceutical/pharmaceutical candidate with functionalities that are better documented than those of health foods in general. Studies have demonstrated that C-phycocyanin has antioxidant and antitumor properties and potential activities against other diseases. However, its large-scale purification remains problematic and expensive. The aim of this work was to establish the best process for obtaining C-phycocyanin of different purities for different applications. The first step of this study was the maximization of the ultrafiltration process. Under the best ultrafiltration conditions, we evaluated the application of ultrafiltration, precipitation, and ion exchange chromatography (expanded and fixed beds) in different sequences and their effects on C-phycocyanin recovery and purification. It was possible to obtain C-phycocyanin that could be used as food dye with purity of 0.95 employing only diafiltration/ultrafiltration. With different process configurations, we obtained extracts that could be used as cosmetic dye with purity of 2.1 and biomarkers with purity of 3.0 , and for therapeutic and biomedicine applications with an analytical grade (purity > 4.0).
\end{abstract}

Keywords: Downstream, Bioproducts, Degree of purity, Commercial purity.

\section{INTRODUCTION}

The biotechnology market is continuously growing; it had a value of US\$161 billion in 2014 and is estimated to reach US $\$ 278$ billion by 2020 (Persistance, 2015). The total market value for phycobiliprotein products (including fluorescent agents) in 2013 was estimated to be greater than US\$ 60 million. Phycocyanin is mainly obtained from cyanobacteria, such as Spirulina, and some reports show a decrease in the market prices, because more companies are focusing on the production and commercialization of microalgal compounds. However, prices are still high owing to the process costs associated with the extraction and purification of intracellular metabolites (Cuellar-Bermudez et al., 2015).

C-phycocyanin (C-PC) is a photosynthetic pigment of the phycobiliprotein group and is present in cyanobacteria, red algae, and cryptomonads, which have wide usage and great economic potential. In addition to its use as a food colorant (Martelli et al., 2014; Pignolet et al., 2013), C-PC acts as a stimulant of the immune defense system (Eriksen, 2008), has shown anticancer and anti-inflammatory capacities (Reddy et al., 2003), and can be used in the prevention and treatment of some neurological disorders and neurodegenerative diseases like Alzheimer's and Parkinson's (Rimbau et al., 1999). It also can be used as a biochemical marker in microscopy and cytometry

*Corresponding author. E-mail address: dqmsjk@furg.br 
because of its fluorescent properties (Vonshak, 2002). Positive health effects have been related to intake of purified C-PC. Although most of these effects are still not fully understood, the functional resemblances between phycocyanorubin and the natural, physiological antioxidant bilirubin have been recognized (Das, 2015).

Lower-purity C-PC can be used as a biocolorant in the food and cosmetics industries at a cost of approximately US $\$ 0.35$ per gram; higher purity C-PC is analytical grade, thus its cost can reach US\$4,500.00 per gram (Abalde et al., 1998; Delhi, 2014). The major differences in C-PC prices are due to the obstacles in its purification process, such as multilayered cell walls and large amounts of contaminants (Bermejo et al., 1997; Bermejo Román et al., 2002). Removal of these contaminants requires a complex experimental procedure, comprising multiple steps, and is time consuming, which may lead to an increase in production costs. For production of analytical-grade C-PC, usually chromatographic steps are applied. However, resin chromatography columns are limited by their slow mass transfer rates, thus requiring a higher flow rate to achieve sufficient productivity. This procedure directly increases facility and equipment related expenses, as well as the need for associated hardware, supporting systems, and facilities (Reichert et al., 2002; Gottschalk, 2008; Jacquemart et al., 2016).

The purification of any biotechnological product generally involves precipitation, centrifugation, ultrafiltration, or biphasic aqueous system steps or combinations of these steps (Ling et al., 2004), followed byon of phycobilipro one or more chromatographic steps such as ion exchange, affinity, or adsorption chromatography. Finalization usually involves a step of gel filtration, drying, crystallization, or freezedrying of the product of interest (Harrison, 2003; Prasad, 2012). The downstream stage can account for $50-80 \%$ of total production costs, depending on the biochemical characteristics of the compound and the purity ratio that needs to be achieved (Molina Grima et al., 2003). Multiple processes to achieve different final purities are rarely developed in studies that seek to obtain a biotechnological product of a determined purity.

Several techniques have been optimized to purify C-PC from the microalgae Spirulina (Antelo et al., 2015; Kamble et al., 2013; Kumar et al., 2014; Moraes and Kalil, 2009; Ramos et al., 2010), and from other microalgae (Benedetti et al., 2006; Abalde et al.,
1998, Sørensen et al., 2013). However, a few works used membrane separation processes (Sørensen et al., 2013). Despite their large applicability, membrane separation processes have only been used in a few studies for the purification of phycobiliproteins produced by this microalgae. Ultrafiltration (UF) is a membrane separation process used extensively in protein separation (Golunski et al., 2011; Lemes et al., 2014; Muller et al., 2003), which possesses several characteristics that ensure minimum denaturation, deactivation, and/or degradation of highly labile biological products. The molecular weight of C-PC may vary from 112 to $280 \mathrm{kDa}$, based on its monomeric constitution, which can be affected by the conditions of the medium, such as temperature and $\mathrm{pH}$. Even though trimer and hexamer conformations are the more stable forms of $\mathrm{C}-\mathrm{PC}$, on dissociating, they may form monomeric structures of molecular weights between 30 and $40 \mathrm{kDa}$ (Patel et al., 2005; Bloomfield and Jennings, 1969; Szalontai et al., 1987; Scheer and Kufer, 1977; Kao et al., 1975; Oi et al., 1982).

Purification processes to provide C-PC in different degrees of purity, using a minimum number of steps, are of high industrial and commercial value. At present, few studies have evaluated the development of a process with multiple scalable steps to obtain C-PC of different purities. The goals of this study were to establish the best conditions for C-PC purification via UF and the optimal sequence of steps, including expanded-bed ion exchange chromatography using crude extract containing cell debris, to be used in the purification and recovery of C-PC of different degrees of purity for different applications.

\section{METHODOLOGY}

\section{C-phycocyanin extraction}

The biomass from an $S$. platensis LEB 52 culture (Costa et al., 2000) was dried at $313 \mathrm{~K}$ to a moisture content of $12 \%$ and then frozen at $255 \mathrm{~K}$. Mechanical rupturing was carried out by grinding in a ball mill (Model Q298, Quimis, Brazil) to a particle diameter between 0.106 and $0.125 \mathrm{~mm}$. C-PC extraction was carried out according to Moraes et al. (2010), who used water as the solvent. Accordingly, $100 \mathrm{~mL}$ of water was added to $24 \mathrm{~g}$ of biomass which was then maintained for $1 \mathrm{~h}$, without agitation, at $298 \mathrm{~K}$ to obtain a crude extract. If a clarified extract was needed, the crude extract was then centrifuged (CIENTEC CT- 5000R, São Paulo, Brazil) at 8,000 xg for 30 minutes. 


\section{C-phycocyanin purification via ultrafiltration}

In this study, initially the best conditions for the ultrafiltration process in C-PC purification were determined. A dead-end stirred cell (magnetic stirrer, volume $0.2 \mathrm{~L}$ ) was utilized with a $50 \mathrm{kDa}$ polyethersulfone ultrafiltration membrane (MycrodinNadir, Wiesbaden, Germany), which was selected based on previous studies (data not shown). The best conditions of $\mathrm{pH}$, temperature, pressure, and number of cycles of diafiltration (DF) were determined using a design of experiment (DoE) assuming a linear response generated by all the factors. By using two-level fractional factorial design and setting each parameter to "low" and "high" values in a $2_{\mathrm{IV}}^{4-1}$ arrangement (Table 1), it was possible to narrow down the number of runs to 8 instead of the 16 required for full factorial design (Kukovecz et al., 2005). The applied resolution IV results in a meaningful model providing an unique estimation of all main effects and 2 f-interactions (Montgomery, 2001).

Table 1. Range of the factors investigated in the factorial design of C-PC ultrafiltration.

\begin{tabular}{lccc}
\hline Independent variables/levels & -1 & 0 & +1 \\
\hline Temperature $\left({ }^{\circ} \mathrm{C}\right)$ & 4.0 & 14.5 & 25 \\
$\mathrm{pH}$ & 6.0 & 6.5 & 7.0 \\
Pressure $\left(\mathrm{kgf.cm}^{-2}\right)$ & 1.0 & 1.5 & 2.0 \\
Diafiltration cycles & 0 & 2 & 4 \\
\hline
\end{tabular}

According to the results obtained in the experimental design, experiments were performed by varying the number of DF cycles in the ultrafiltration cell. Diafiltration cycles consisted of a $25-\mathrm{mM}$ sodium phosphate buffer ( $\mathrm{pH} 6.5)$ recharged in the ultrafiltration cell. DF cycles of 4, 6, 8, and 10 and their influence on the purification factor and recovery of C-phycocyanin and the permeate flux were evaluated. The experiments were conducted at $\mathrm{pH} 6.5,1.0 \mathrm{kgf} \cdot \mathrm{cm}^{-2}$, and $25^{\circ} \mathrm{C}$. Finally, an evaluation was made of the utilization of diafiltration before ultrafiltration. Ultrafiltration experiments were performed in triplicate.

\section{Development of processes for obtaining C-phycocyanin with different degrees of purity}

The following purification techniques, individually and combined in different sequences, were used to obtain C-PC of different purities: ultrafiltration, ammonium sulfate precipitation, and fixed- and expanded-bed ion exchange chromatography (Figure 1). Complete C-PC purification process experiments were carried out unreplicated.

\section{Ammonium sulfate precipitation}

For C-PC purification using two-step ammonium sulfate precipitation, the methodology presented by Silva et al. (2009) was modified for fractionation times, with applications of 1, 2, 4, 6, and 14 hours. The C-PC clarified extract was fractionated with solid (NH4)2SO4 at $25{ }^{\circ} \mathrm{C}$ with $0-20 \%$ and $20-50 \%$ saturations in the first and second steps, respectively. In the first step, ammonium sulfate was added to the sample until a concentration equivalent to 20 $\%$ saturation was obtained. The addition occurred under constant agitation for the first $30 \mathrm{~min}$, and the solution was maintained under refrigeration until the experimental period had ended as shown in Table 1 . After this period, the sample was centrifuged $(12,000$ $\times g$ at $298 \mathrm{~K}$ for $20 \mathrm{~min}$ ) and the precipitate was discarded. In the second step, ammonium sulfate was added to the supernatant until $50 \%$ saturation was attained, similar to the previous saturation. The solution was maintained for the same period as the first fractionation and then centrifuged. The supernatant was discarded, and the precipitate was dissolved in $0.05 \mathrm{M}$ phosphate potassium buffer ( $\mathrm{pH} 7.0)$.

\section{Diafiltration/ultrafiltration (DF/UF)}

The same apparatus used in the study of C-PC purification by ultrafiltration was used. The process was conducted at $298 \mathrm{~K}, \mathrm{pH}$ of 6.5 , and nitrogen gas pressure of $1.0 \mathrm{kgf} \cdot \mathrm{cm}^{-2}$. The system was operated in $\mathrm{DF} / \mathrm{UF}$ mode, with 6 cycles of diafiltration prior to concentration of the extract in ultrafiltration mode. The C-PC clarified extract was fed into the system, which was operated at 40 minutes per cycle. The last cycle finished at an initial volume/final volume ratio of 5. After each assay, the concentration and purity of C-PC were quantified. DF/UF was also used after the precipitation and chromatographic steps for salt removal.

\section{Fixed-bed ion exchange chromatography}

A volume of $50 \mathrm{~mL}$ of the extract containing the C-PC obtained in an earlier step (Figure 1) was loaded onto a C10/20 GE Healthcare(r) (Uppsala, Sweden) column with Q-Sepharose Fast Flow(r) resin (GE Healthcare, Uppsala, Sweden), previously equilibrated in $0.025 \mathrm{M}$ Tris- $\mathrm{HCl}$ buffer $\mathrm{pH} 6.5$ at 40 $\mathrm{cm} \cdot \mathrm{h}^{-1}$. The non-adsorbed proteins were removed by washing with the same equilibrium buffer. Pre-elution using $0.1 \mathrm{M} \mathrm{NaCl}$ and an elution with a linear gradient of $0-1 \mathrm{M} \mathrm{NaCl}$ with a gradient volume of $50 \mathrm{~mL}$, both in $0.025 \mathrm{M}$ Tris- $\mathrm{HCl}$ buffer $\mathrm{pH} 5.0$ (Moraes and Kalil, 


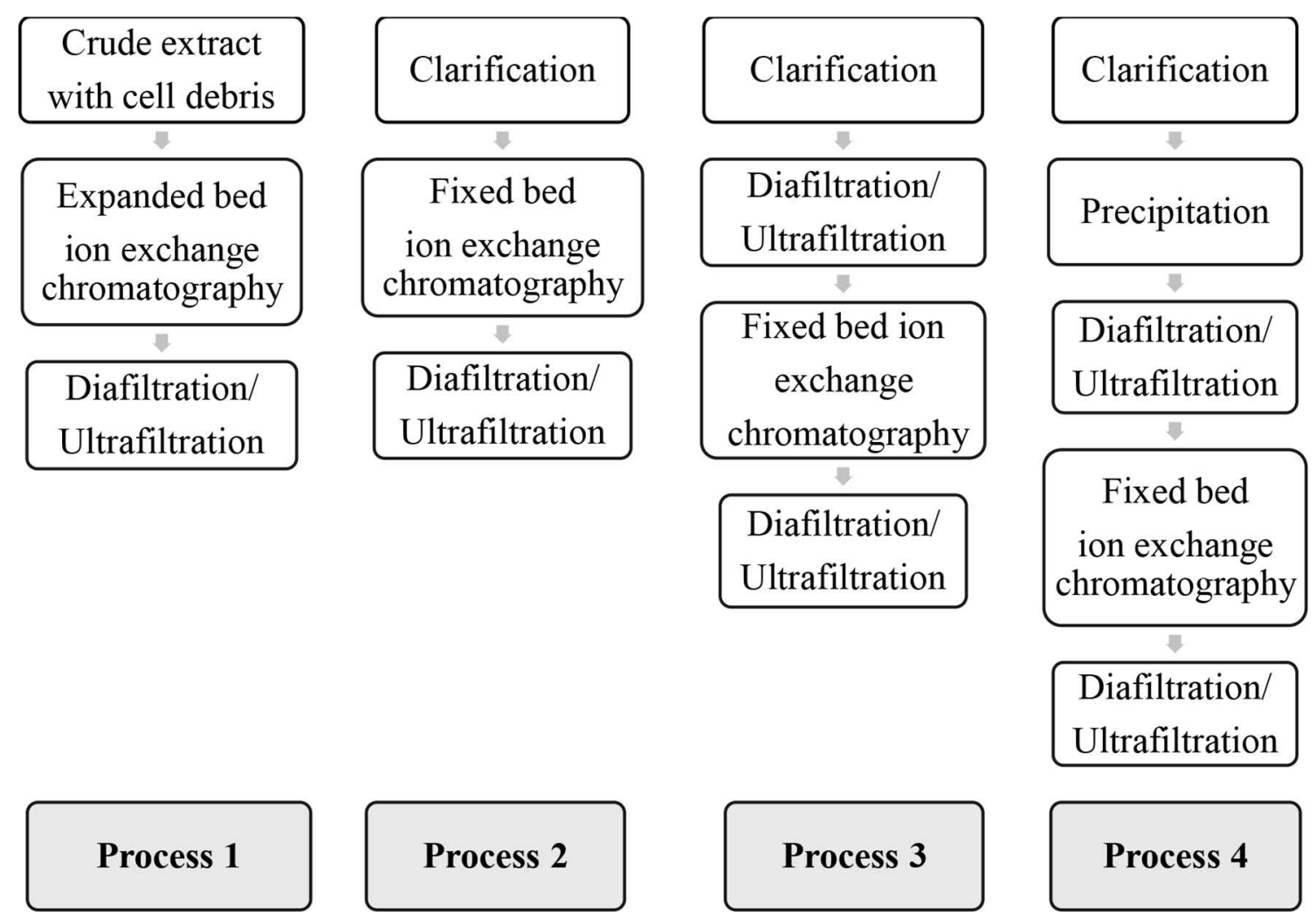

Figure 1. Schematic diagram of the C-PC purification processes studied $(1,2,3,4)$ using different steps.

2009), were performed. Samples were collected for evaluation of C-PC concentration, extract purity, and protein content, which was determined by reading the absorbance at $280 \mathrm{~nm}$. The experiments were performed at $298 \mathrm{~K}$. The most purified fractions were mixed and utilized in subsequent process steps.

\section{Expanded-bed ion exchange chromatography}

For purification experiments in expanded-bed mode, the methodology reported by Moraes et al. (2011) was applied, but replacing the resin used in that study with Streamline DEAE(r) (GE Healthcare, Uppsala, Sweden). A Streamline(r) 25 column containing ion exchange resin (10 $\mathrm{cm}$ of bed height) was used in all experiments. The column was equilibrated with 0.025 $\mathrm{M}$ sodium phosphate buffer ( $\mathrm{pH} 7.5$ ) with an upward flow rate to obtain an expansion degree of twice its height $(20 \mathrm{~cm}$ of bed height) until the bed was stable. In all assays, a $220 \mathrm{~mL}$ portion of C-PC extract at $\mathrm{pH}$ 7.5 with cell debris was loaded onto the column, with an upward flow rate of $123 \mathrm{~cm} \cdot \mathrm{h}^{-1}$, maintaining the degree of expansion. After applying the whole sample volume, the column was washed with the starting buffer in the expanded mode to remove the remaining cells and non-adsorbed proteins. After washing, the bed was allowed to settle in the column. The adaptor was then moved down to the surface of the settled bed $(10 \mathrm{~cm})$, and a pre-elution using $0.1 \mathrm{MNaCl}$ and an elution with a linear gradient of $0.1-1 \mathrm{M} \mathrm{NaCl}$ with a gradient volume of $220 \mathrm{~mL}$, both in $0.025 \mathrm{M}$ Tris$\mathrm{HCl}$ buffer $\mathrm{pH} 6.5$ in downward flow, were carried out. Fractions were collected for evaluation of their C-PC concentration, extract purity, and protein content, which was determined from the absorbance at $280 \mathrm{~nm}$. The feed extract $\mathrm{pH}$ in this study was selected based on the previous evaluation of adsorption parameters (Janson, 2012). The other process conditions were based on the study by Moraes et al. (2015), who compared the use of Streamline Q XL with Streamline DEAE.

\section{C-phycocyanin concentration and recovery}

C-PC concentration was calculated using Eq. 1, which was previously described by Bennett and Bogorad (1973) with modifications in wavelength (Moraes and Kalil, 2009; Silveira et al., 2008). The 
recovery (Eq. (2)) was calculated using the ratio of the amount of C-PC collected to the amount of C-PC loaded.

$$
\mathrm{C}-\mathrm{PC}\left(\mathrm{mg} \cdot \mathrm{mL}^{-1}\right)=\frac{\left(A 620-0.474 A_{652}\right)}{5.34}
$$

Recovery $(\%)=$

$\frac{\mathrm{C}-\mathrm{PC}\left(\mathrm{mg} \cdot \mathrm{mL}^{-1}\right) \times \text { collected volume }(\mathrm{mL})}{\mathrm{C}-\mathrm{PC} \text { initial extract }\left(\mathrm{mg} \cdot \mathrm{mL}^{-1}\right) \times \text { initial volume }(\mathrm{mL})} \times 100$

\section{Extract purity and purification factor}

C-PC extract purity was determined using the $\mathrm{A}_{620} / \mathrm{A}_{280}$ ratio (Abalde et al., 1998), obtained in a spectrophotometer (SHIMADZU UV-1800, Kyoto, Japan). The purification factor was calculated using the purity of each fraction and the purity of the step feed extract ratio (Silveira et al., 2008).

\section{RESULTS AND DISCUSSION}

\section{C-phycocyanin purification via ultrafiltration}

The purification of C-PC from S. platensis via ultrafiltration involves a combination of different operational variables, and determination of these process conditions is required to achieve maximum efficiency. The temperature $\left(4-25^{\circ} \mathrm{C}\right)$ and $\mathrm{pH}(6.0$ to 7.0) ranges evaluated were selected according to the stability of C-phycocyanin at these levels (Pumas et al., 2011; Sarada et al., 1999). The pressure values (1.0 to $2.0 \mathrm{kgf} \cdot \mathrm{cm}^{-2}$ ) were selected according to preliminary studies and the number of diafiltration cycles (0-4) was selected according to Singh et al. (2009), who used 4 cycles for C-phycocyanin ultrafiltration. Coded and real values for the evaluated conditions, as well as the recovery and C-phycocyanin purification factor for each run of the fractional factorial design, are summarized in Table 2.

The C-PC recovery varied between 60 and $99 \%$, and the purity values of the C-PC extracts ranged between 0.70 and 0.82 , classifying them as food grade according to Rito-Palomares et al. (2001).The final concentration of C-PC in all runs was similar, starting from an initial solution with concentration of $4.26 \pm 0.75 \mathrm{mg} \cdot \mathrm{mL}^{-1}$ and ending the process with a concentration of $17.02 \pm 1.32 \mathrm{mg} \cdot \mathrm{mL}^{-1}$.

To study the model significance, the influence of single factors (main effects) and higher-factors interaction on the purification factor (PF) and the recovery results should be evaluated by testing the probability (appropriate probability plots). According to Myers et al. (2009), three- and higher-order interactions can be considered insignificant and therefore negligible for further evaluation, leaving the single- and two-factor interactions as the most important for applied design.

Determination of the significant main and interaction effects of factors influencing the C-PC purification factor indicated that the single-factor number of diafiltration cycles is important, whereas the other factors and interactions were insignificant. In C-PC recovery, temperature and the interaction between temperature and diafiltration (effect of temperature differs depending on the number of diafiltration cycles) are the important factors. These parameters have a $p$ value $\leq 0.003$, indicating a group of factors with higher significance. The present fractional factorial model resulted in predictions for $\mathrm{PF}$ with an $R^{2}$ of 0.9911 and adjusted $R$-squared of 0.9990 for C-PC recovery. The previous results were verified by a Pareto chart (Figure 2) displaying the $t$-values of the effects, which are proportional to their degree of significance.

Table 2. Coded and real values (in parentheses) of temperature (T), pressure (P), $\mathrm{pH}$ and diafiltratrion cycles (DF) for the fractional factorial design, recovery $(\mathrm{R})$, and purification factor $(\mathrm{PF})$ of C-phycocyanin.

\begin{tabular}{|c|c|c|c|c|c|c|}
\hline Run & $\mathrm{T}\left({ }^{\circ} \mathrm{C}\right)$ & $\mathrm{P}\left(\mathrm{kgf.cm}{ }^{-2}\right)$ & $\mathrm{pH}$ & $\mathrm{DF}$ & PF (fold) & $\mathrm{R}(\%)$ \\
\hline 1 & $-1(4.0)$ & $-1(1.0)$ & $-1(6.0)$ & $-1(0)$ & 1.38 & 86 \\
\hline 2 & $1(25.0)$ & $-1(1.0)$ & $-1(6.0)$ & $1(4)$ & 1.54 & 92 \\
\hline 3 & $-1(4.0)$ & $1(2.0)$ & $-1(6.0)$ & $1(4)$ & 1.72 & 90 \\
\hline 4 & $1(25.0)$ & $1(2.0)$ & $-1(6.0)$ & $-1(0)$ & 1.42 & 99 \\
\hline 5 & $-1(4.0)$ & $-1(1.0)$ & $1(7.0)$ & $1(4)$ & 1.53 & 89 \\
\hline 6 & $1(25.0)$ & $-1(1.0)$ & $1(7.0)$ & $-1(0)$ & 1.36 & 95 \\
\hline 7 & $-1(4.0)$ & $1(2.0)$ & $1(7.0)$ & $-1(0)$ & 1.35 & 60 \\
\hline 8 & $1(25.0)$ & $1(2.0)$ & $1(7.0)$ & $1(4)$ & 1.54 & 91 \\
\hline 9 & $0(14.5)$ & $0(1.5)$ & $0(6.5)$ & $0(2)$ & 1.52 & 90 \\
\hline 10 & $0(14.5)$ & $0(1.5)$ & $0(6.5)$ & $0(2)$ & 1.47 & 82 \\
\hline 11 & $0(14.5)$ & $0(1.5)$ & $0(6.5)$ & $0(2)$ & 1.57 & 93 \\
\hline
\end{tabular}



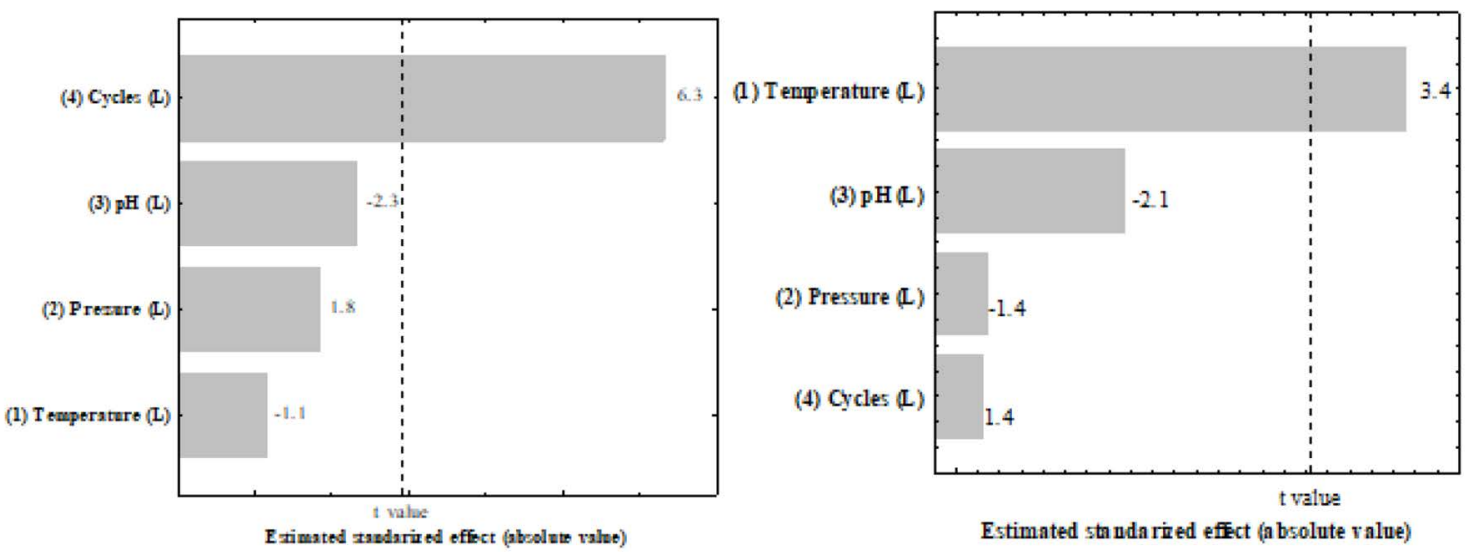

Figure 2. Pareto charts of standardized effects for (a) purification factor and (b) recovery of C-phycocyanin.

The use of 4 diafiltration cycles increased the purification factor, probably due to resuspension of solids at the membrane surface and rehomogenizing of the solution, which enabled a reduction in polarization and fouling, allowing the passage of contaminants that had previously accumulated on the membrane.

An increase in C-PC recovery was obtained at the higher temperature $\left(25^{\circ} \mathrm{C}\right)$. This increase can be attributed to higher retention due to a slight increase in the molar mass of C-PC with an increase in temperature. This may be attributed to the presence of (at least) two sets of chromophores in C-PC that are affected to different degrees by heat, with conformational changes in the monomeric protein as reported by Scheer and Kufer (1977). This increase in molecular weight can lead to a higher retention in the retentate. The variation of process conditions is highly important since they can reduce the $\mathrm{C}$-PC loss by reducing the dissociation into $\alpha \beta$-monomers of size lower than $50 \mathrm{kDa}$ (Oi et al., 1982). This loss reduction can be confirmed by the recovery values higher than $90 \%$ found in this work. In addition, according to Vincent-Vela et al. (2012), the resistance to fouling at the beginning of the process and the resistance of the cake layer formed on the membrane are reduced with increased temperature; however, above a certain temperature, this effect was not observed.

A new set of experiments was performed to evaluate different numbers of diafiltration cycles with temperature fixed at $25^{\circ} \mathrm{C}$, at which the higher $\mathrm{PF}$ and recovery were obtained. The nonsignificant parameter of pressure was fixed at $1.0 \mathrm{kgf} \cdot \mathrm{cm}^{-2}$ because of less $\mathrm{N}_{2}$ consumption and the $\mathrm{pH}$ was fixed at 6.5 because this is the $\mathrm{pH}$ value for the chromatographic steps (Moraes et al., 2009) used in later tests.

The increase in cycle number from 4 to 6 significantly improved the purification factor of the
C-PC from 1.49 to 1.65 ; however, when more than 6 cycles were used, no significant increase in this factor was observed (Figure 3). This behavior can be attributed to the passage of most contaminant particles smaller than the nominal retention membrane (50 $\mathrm{kDa}$ ) during the first 6 cycles. For C-PC recovery, the applications of 4 and 6 cycles were statistically equal and higher than $90 \%$ (Figure 3 ), with a reduction in its value when more than 6 cycles were applied. These results demonstrate that the application of 6 cell recharge cycles is better for enhancing the purification process, obtaining a C-PC extract with a purity degree of 0.91 .

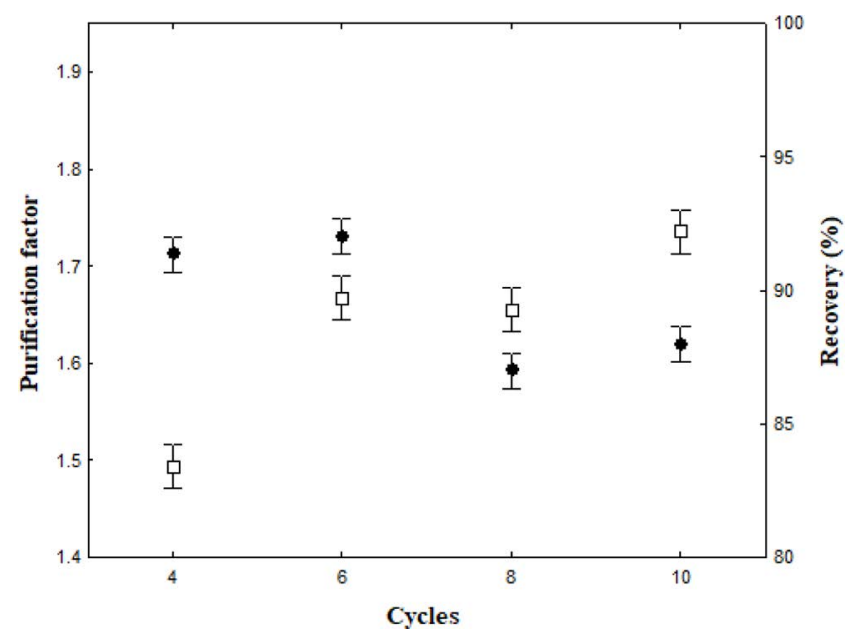

Figure 3. Values of C-phycocyanin purification factor ( $\square$ ) and recovery $(\bullet)$ obtained with different numbers of diafiltration cycles.

To obtain a product with a higher purity, the buffer recharge cycles (diafiltration) were performed before the concentration by ultrafiltration and compared with tests carried out previously. A significant difference was observed for the purification factor when the diafiltration was applied prior to concentration. The purification factor was $1.79 \pm 0.03$, a value $8 \%$ above 
that when the diafiltration process was applied after concentration of the extract, reaching a purity degree of 0.95 .

This improvement in the purification may possibly be due to lower membrane polarization caused by buffer addition at the beginning of the process, as was identified by $\mathrm{Li}$ et al. (2009). Baldasso et al. (2011) found that diafiltration is highly efficient when applied with small feed volumes and a high number of cycles. It has been found that fouling caused by proteins did not depend on their individual size but on their ability to form aggregates (Güell and Davis, 1996), and increased protein concentration can cause increased aggregation (Cromwell et al., 2006). Protein aggregates deposited on the membrane surface and additional molecules can lead to the formation of a multilayer buildup on the membrane surface. Because of the colloidal property of the protein layer, buffer passing by cannot remove the fouling (Li et al., 2009).

\section{Ammonium sulfate precipitation}

Precipitation with ammonium sulfate is a technique frequently employed for C-PC purification (Moraes and Kalil, 2009; Soni et al., 2006), and there has been extensive study of its process conditions (Silva et al., 2009). However, a previous evaluation of the application of this technique at different times was not found. Table 3 shows the times applied at each stage of fractional precipitation under the conditions determined by Silva et al. (2009). The times of 14 (overnight), 6, 4, and 2 hours showed no significant difference for the purification factor or recovery, indicating that 2 hours at each step of fractionation can be used for C-PC precipitation and for reaching a final extract purity of 1.54. Sørensen et al. (2013), evaluating two precipitation process in the purification of C-phycocyanin from the heterotrophic microalgae G. sulfuraria, obtained an extract purity of 1.1 ; however, they reached a recovery higher than $90 \%$.

Table 3. Times used for ammonium sulfate precipitation of C-PC with obtained purification factors and recovery percentages

\begin{tabular}{lcc}
\hline $\begin{array}{l}\text { Fractionation Step } \\
\text { time (hours) }\end{array}$ & PurificationFactor & Recovery (\%) \\
\hline 1 & $1.67^{\mathrm{b}} \pm 0.01$ & $63^{\mathrm{b}} \pm 0$ \\
2 & $2.64^{\mathrm{a}} \pm 0.10$ & $79^{\mathrm{a}} \pm 6$ \\
4 & $2.63^{\mathrm{a}} \pm 0.10$ & $73^{\mathrm{a}} \pm 1$ \\
6 & $2.64^{\mathrm{a}} \pm 0.12$ & $74^{\mathrm{a}} \pm 0$ \\
14 & $2.60^{\mathrm{a}} \pm 0.06$ & $72^{\mathrm{a}} \pm 9$ \\
\hline
\end{tabular}

Means followed by the same letters in columns do not differ statistically using Tukey's test $(\mathrm{p} \leq 0.05)$.

\section{C-phycocyanin purification process}

The production of C-PC with different degrees of purity requires the development of various purification protocols to reduce the process time using fewer steps and achieving higher product recovery. The C-PC purification steps used were fractional precipitation with ammonium sulfate, DF/UF, and fixed- and expanded-bed ion exchange chromatography. To ensure the consistency of samples in all experiments, the same batch of dry biomass of S. platensis was used. A summary of the processes assessed in this study is shown in Figure 1.

The choice of steps for each process was based on other processes and techniques used for C-PC purification found in the literature (Moraes and Kalil, 2009; Song et al., 2013). In the first purification process, where expanded-bed ion exchange chromatography was used, the crude broth containing the cells was diluted, and the $\mathrm{pH}$ was adjusted to working conditions. DF/UF was used instead of dialysis to remove salts from the extract. This technique can contribute to purification and concentration of the extract, in addition to salt removal.

The results for purity, purification factor, and recovery obtained after each step of each process are shown in Table 4 and show that different processes produced different purities, e.g., food grade (2.12, 2.41, 2.96, and 3.00) and analytical grade (4.1) purities according to Rito-Palomares et al. (2001). Furthermore, the extracts obtained also fit into the classification used by companies that sell C-PC, with purities between 0.5 to 1.5 for use as a food dye, between 1.50 and 2.50 for use as a cosmetic dye, between 2.5 and 3.5 for use as a biomarker, and a purity greater than 4 for use in biomedical applications and as a therapeutic agent.

Process 1 used expanded-bed ion exchange chromatography for C-PC adsorption onto Streamline DEAE resin, followed by a DF/UF step. Some studies have evaluated the use of expanded-bed Streamline DEAE resin (Bermejo et al., 2006; Bermejo and Ramos, 2012); however, only Moraes et al. (2015) has used unclarified C-PC crude extract with this resin and compared the results with those when using Streamline QXL resin. For both resins, the authors obtained lower purities than what we obtained in this work.

As observed by Moraes et al. (2011), the preelution step promoted the removal of some protein contaminants that were weakly bound to the resin. This can be observed in the chromatogram in Figure 4 in 
Table 4 . Evaluation of purity, purification factor and recovery for each step in each process tested for C-PC purification.

\begin{tabular}{|c|c|c|c|c|}
\hline Process & Step & Extractpurity & Purificationfactor & Recovery (\%) \\
\hline \multirow{4}{*}{1} & Initial & 0.50 & 1.0 & 100 \\
\hline & $\begin{array}{l}\text { Expanded bed ion exchange } \\
\text { chromatography }\end{array}$ & 2.41 & 4.8 & 60 \\
\hline & Diafiltration/Ultrafiltration & 2.96 & 1.2 & 83 \\
\hline & Global & 2.96 & 5.9 & 50 \\
\hline \multirow{4}{*}{2} & Initial & 0.58 & 1.0 & 100 \\
\hline & Fixed bed ion exchange chromatography & 2.12 & 3.7 & 73 \\
\hline & Diafiltration/Ultrafiltration & 2.12 & 1.0 & 92 \\
\hline & Global & 2.12 & 3.7 & 68 \\
\hline \multirow{5}{*}{3} & Initial & 0.57 & 1.0 & 100 \\
\hline & Diafiltration/Ultrafiltration & 0.95 & 1.7 & 93 \\
\hline & Fixed bed ion exchange chromatography & 3.00 & 3.2 & 58 \\
\hline & Diafiltration/Ultrafiltration & 3.00 & 1.0 & 96 \\
\hline & Global & 3.00 & 5.3 & 51 \\
\hline \multirow{6}{*}{4} & Initial & 0.57 & 1.0 & 100 \\
\hline & Precipitation & 1.54 & 2.7 & 81 \\
\hline & Diafiltration/Ultrafiltration & 2.12 & 1.4 & 95 \\
\hline & Fixed bed ion exchange chromatography & 4.10 & 1.9 & 56 \\
\hline & Diafiltration/Ultrafiltration & 4.10 & 1.0 & 97 \\
\hline & Global & 4.10 & 7.2 & 42 \\
\hline
\end{tabular}

the 280-nm absorbance curve, which represents total proteins. Bermejo and Ramos (2012) used Streamline DEAE resin with a clarified extract of C-PC and obtained a purification factor of 4.5 , resulting in a final extract with 0.87 purity in the expanded-bed chromatography step and a recovery of $79 \%$. In the current study, starting with an unclarified extract, we obtained a purity of 2.41 (4.8 times purer than the initial extract, for an increase of nearly $400 \%$ in extract purity) and a recovery of $60 \%$. The expandedbed chromatography enabled the utilization of a crude broth containing cells and cell debris and eliminated steps, such as ammonium sulfate precipitation and gel permeation chromatography, which are commonly used in purification protocols. This step also reduced the total time of the process (Kamble et al., 2013).

In the processes studied, the main purpose of the diafiltration step was the removal of the salts used in the ion exchange chromatography elution steps and sulfate salts employed during precipitation of the sample concentrate. Furthermore, as the solution is forced through a membrane with pores $50 \mathrm{kDa}$ in size, diafiltration allows an increase in the purity of the diafiltered solution in some situations where the extract still contains contaminants.

Processes 1 and 2 differed only in the ion exchange chromatography operation mode, where process 1 used the expanded-bed mode and process 2 used

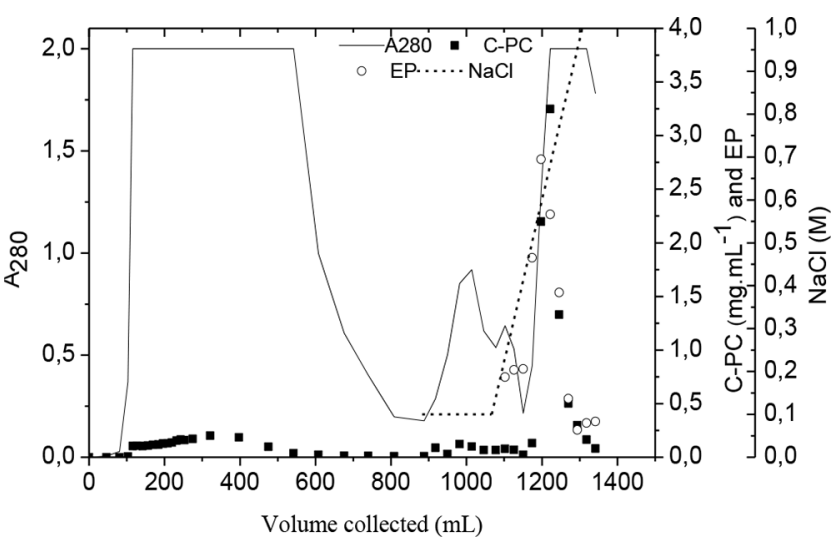

Figure 4. Chromatogram of C-PC purification in expanded bed on Streamline DEAE using stepwise elution $(0.1 \mathrm{M})$ combined with gradient elution $(0.1-1 \mathrm{M})$.

the fixed-bed mode, with their corresponding ion exchange matrix. In process 2 , we used a fixed-bed ion exchange chromatography step, optimized by Moraes and Kalil (2009), employing the strong anion exchanger Q-Sepharose FF, as used by Abalde et al. (1998), Moraes and Kalil (2009), Silveira et al. (2008) and Sørensen et al. (2013) for C-PC purification, and subsequent $\mathrm{DF} / \mathrm{UF}$ for the extract concentration. Using this process, it was possible to obtain C-PC with a purity of 2.12. The values obtained agree with those found by Moraes and Kalil (2009) using fixed-bed ion exchange chromatography with a clarified extract and without a prior purification step. This step allowed 
the highest bioproduct purification (approximately 14 $\%$ higher) and higher productivity because the fixed bed works with a flow rate of $40 \mathrm{~cm} \cdot \mathrm{h}^{-1}$, whereas the expanded bed works with a flow rate of $123 \mathrm{~cm} \cdot \mathrm{h}^{-1}$.

In process 3, DF/UF was used before and after the fixed-bed ion exchange chromatography, presenting equivalent results to those obtained in process 1 with a purity between 2.5 and 3.5, which can be used commercially for biomarkers, with an average cost of $\$ 1,500.00$ per gram (Delhi, 2014). Commercial food grade C-PC (purity between 0.75 and 1.5 ) can be obtained from the first DF/UF in this process, which provided an extract with a purity of 0.95 and a high recovery of $93 \%$.

Process 4 produced an analytical grade (EP > 4.0) extract, which can cost up to $\$ 4,500.00$ per gram (Delhi, 2014). In the first step of this process, ammonium sulfate precipitation was used under the conditions that had been previously determined. This precipitation technique provides increased purity with relatively high recovery, in addition to being a lowcost and simple application (Moraes and Kalil, 2009; Silva et al., 2009). The subsequent DF/UF, in addition to removing the ammonium salt from the sample that would inhibit adsorption by the ion exchange resin, allowed a further increase in the degree of purity of the extract, with high recovery $(95 \%)$. Precipitation followed by DF/UF presented a total recovery of $77 \%$ and an extract purity of 2.12 , which was similar to that obtained in process 2 , showing that this process is more suitable for obtaining a C-PC extract for application as a cosmetic dye.

In process 4 , the concentrated extract was fed into the fixed-bed column using the same methodology applied in processes 2 and 3. Figure 5 shows the chromatogram obtained, and we verified that the preelution removed some contaminating proteins (as can be seen by the readings at $280 \mathrm{~nm}$ ). Three fractions were obtained in the elution phase with total extract purity of 4.1 and a recovery of $56 \%$. It is generally accepted that, for an increase in the purification of a biotechnological product, there is a loss in recovery, and it is necessary to choose between these two outcomes in the process (Wheelwright, 1989).

After chromatography, DF/UF did not increase purity and produced a final concentration of 11.1 $\mathrm{mg} \cdot \mathrm{mL}^{-1}$. The final recovery of process 4 was $42 \%$, with a purification factor of 7.2 , which is slightly higher than the 6.3 obtained by Moraes and Kalil (2009). Song et al. (2013) obtained C-PC with a purity of 5.32 and a recovery of $42 \%$ using precipitation

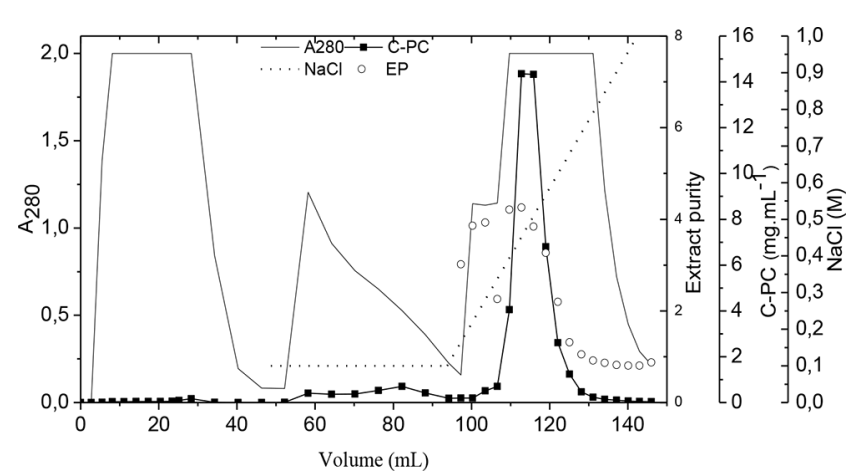

Figure 5. Chromatogram of C-PC purification in a fixed bed on Q-Sepharose $\mathrm{FF}^{\circledR}$ using stepwise elution combined with gradient elution (0.1-1 M).

with ammonium sulfate and subsequent passage through three chromatographic columns (hydrophobic interaction, ion exchange, and gel permeation). Process 4 described here has the advantage of using only one chromatography step.

Without the use of DF/UF as an alternative to dialysis, the total time required for the purification process of C-PC can be considerably reduced. This study shows the development of processes for obtaining C-PC, in accordance with required purities, with a minimum number of steps while maintaining high recovery levels. After the DF/UF step in process 3, C-PC that could be used as a food dye was obtained and, at the end of same process, produced C-PC that could be used as a biomarker. Process 4 produced C-PC appropriate for use as a colorant in cosmetics after precipitation and DF/UF steps, with greater recovery, and, at the end of this process, the C-PC obtained was analytical grade and thus suitable for therapeutic and biomedical uses.

\section{CONCLUSION}

Starting with a clarified extract of C-PC, a C-PC extract with purity of 0.95 suitable for use as food dye (purity between 0.75 and 1.5) can be obtained by using only ultrafiltration after 6 diafiltration cycles. A purity suitable for use as coloring in cosmetics (between 1.5 and 2.5) can be reached with the use of ammonium sulfate precipitation, followed by ultrafiltration. To get C-PC for biomarkers (between 2.5 and 3.5), the use of expanded-bed ion exchange chromatography followed by ultrafiltration is the most suitable. To obtain analytical grade C-PC (purity $>4.0$ ), a sequence involving precipitation, ultrafiltration, fixed-bed ion exchange chromatography, and ultrafiltration should be used. 


\section{ACKNOWLEDGMENTS}

The authors are grateful to CAPES and CNPq for their financial support and to the Laboratory of Biochemical Engineering of Federal University of Rio Grande for the donation of the cyanobacteria.

\section{NOMENCLATURE}

$\mathrm{A}_{620} \quad$ Absorbance at wavelength $620 \mathrm{~nm}[-]$

$\mathrm{A}_{652} \quad$ Absorbance at wavelength $652 \mathrm{~nm}[-]$

$\mathrm{A}_{280} \quad$ Absorbance at wavelength $280 \mathrm{~nm} \mathrm{[-]}$

C-PC C-phycocyanin concentration $\left[\mathrm{mg} \cdot \mathrm{mL}^{-1}\right]$

\section{REFERENCES}

Abalde, J., Betancourt, L., Torres, E., Cid, A. and Barwell, C., Purification and Characterization of Phycocyanin From the Marine Cyanobacterium Synechococcus sp. IO9201, Plant Science, 136(1), 109-120 (1998).

Antelo, F.S., Costa, J.A.V. and Kalil, S.J., Purification of C-phycocyanin from Spirulina platensis in Aqueous Two-phase Systems Using an Experimental Design, Brazilian Archives of Biology and Technology, 58(1), 1-11 (2015).

Bennett, A. and Bogorad, L., Complementary chromatic Adaptation in a Filamentous BlueGreen-Alga. Journal of Cell Biology, 58(2), 419435 (1973).

Bermejo, R., Felipe, M.A., Talavera, E.M. and Alvarez-Pez, J.M., Expanded Bed Adsorption Chromatography for Recovery of Phycocyanins From the Microalga Spirulina platensis, Chromatographia, 63(1-2), 59-66(2006).

Bermejo, R. and Ramos, A., Pilot Scale Recovery of Phycocyanin from Spirulina platensis Using Expanded Bed Adsorption Chromatography, Chromatographia, 75(5-6), 195-204(2012).

Bermejo, R., Talavera, E.M., Alvarez-Pez, J.M. and Orte, J.C. Chromatographic Purification of Biliproteins from Spirulina platensis. Highperformance Liquid Chromatographic Separation of their a and b Subunits, Journal of Chromatography A, 778(1-2), 441-450(1997).

Bermejo-Román, R., Alvaárez-Pez, J.M., AciénFernández, F.G. and Molina-Grima, E., Recovery of Pure B-phycoerythrin From the Microalga Porphyridium cruentum, Journal of Biotechnology, 93(1), 73-85 (2002).

Burgess, R.R. Chapter 20 Protein Precipitation Techniques. in: Methods in Enzymology, (Eds.)
R.B Richard, P.D Murray, 463, Academic Press, Cambridge (2009).

Costa, J.A.V., Linde, G.A., Atala, D.I.P., Mibielli, G.M. and Kruger, R.T., Modelling of Growth Conditions for Cyanobacterium Spirulina platensis in Microcosms, World Journal of Microbiology \& Biotechnology, 16, (1), 15-18 (2000).

Cramer, S.M. and Holstein, M.A., Downstream Bioprocessing: Recent Advances and Future Promise, Current Opinion in Chemical Engineering, 1, (1), 27-37 (2011).

Cromwell, M. E., Hilario, E., and Jacobson, F. Protein aggregation and bioprocessing. The AAPS Journal, 8(3), E572-E579 (2006).

Cuellar-Bermudez, S.P., Aguilar-Hernandez, I., Cardenas-Chavez, D.L., Ornelas-Soto, N., RomeroOgawa, M.A. and Parra-Saldivar, R., Extraction and Purification of High-value Metabolites from Microalgae: Essential Lipids, Astaxanthin and Phycobiliproteins, Microbial Biotechnology, 8, (2), 190-209 (2015).

Das, D., Algal Biorefinery: An Integrated Approach. Springer International Publishing, Cham (2015).

Delhi, Nutraceuticals Private Limited. C-phycocyanin. Gurgaon, India (2014).

Eriksen, N.T., Production of Phycocyanin - A Pigment with Applications in Biology, Biotechnology, Foods and Medicine, Applied Microbiology and Biotechnology, 80, (1), 1-14 (2008).

Evans, D.R.H., Romero, J.K. and Westoby, M., Concentration of Proteins and Removal of Solutes. Guide to Protein Purification, Second Edition, 463, 97-120 (2009).

Gottschalk, U., Bioseparation in Antibody Manufacturing: the good, the bad and the ugly. Biotechnol Prog, 24(3), 496-503 (2008).

Golunski, S., Astolfi, V., Carniel, N., de Oliveira, D., Di Luccio, M., Mazutti, M.A. and Treichel, H., Ethanol Precipitation and Ultrafiltration of Inulinases from Kluyveromyces marxianus. Separation and Purification Technology, 78 (3), 261-265 (2011).

Harrison, R.G., Bioseparations Science and Engineering. Oxford University Press, Oxford (2003).

Janson, J.C., Protein Purification: Principles, High Resolution Methods, and Applications. Wiley, Hoboken, (2012).

Kamble, S.P., Gaikar, R.B., Padalia, R.B. and Shinde, K.D., Extraction and Purification of C-phycocyanin from Dry Spirulina Powder and Evaluating its 
Antioxidant, Anticoagulation and Prevention of DNA Damage Activity, Journal of Applied Pharmaceutical Science, 3(8), 149-153 (2013).

Kao, O.H., Edwards, M.R. and Berns, D.S., Physicalchemical properties of C-phycocyanin isolated from an acido-thermophilic eukaryote, Cyanidium caldarium. Biochemical Journal, 147(1), 63-70 (1975).

Kumar, D., Dhar, D.W., Pabbi, S., Kumar, N. and Walia, S., Extraction and Purification of C-phycocyanin from Spirulina platensis (CCC540), Indian Journal of Plant Physiology, 19(2), 184-188 (2014).

Lemes, A.C., Machado, J.R., Brites, M.L., Luccio, M.D. and Kalil, S.J., Design Strategies for Integrated $\beta$-Galactosidase Purification Processes, Chemical Engineering \& Technology, 37(10), 1805-1812 (2014).

Ling, T.C., Loong, C.M., Tan, W.S., Tey, B.T., Abdullah, W.M.W. and Ariff, A., Purification of Filamentous Bacteriophage M13 by Expanded Bed Anion Exchange Chromatography, Journal of Microbiology, 42(3), 228-232 (2004).

Martelli, G., Folli, C., Visai, L., Daglia, M. and Ferrari, D., Thermal Stability Improvement of Blue Colorant C-phycocyanin from Spirulina platensis for Food Industry Applications, Process Biochemistry, 49(1), 154-159 (2014).

Molina Grima, E., Belarbi, E.H., Acién Fernández, F.G., Robles Medina, A. and Chisti, Y., Recovery of Microalgal Biomass and Metabolites: Process Options and Economics, Biotechnology Advances, 20(7-8), 491-515(2003).

Moraes, C.C., Burkert, J.F.D. and Kalil, S.J., C-phycocyanin Extraction Process for Large-Scale Use, Journal of Food Biochemistry, 34, 133-148 (2010).

Moraes, C.C. and Kalil, S.J., Strategy for a Protein Purification Design Using C-phycocyanin Extract, Bioresource Technology, 100(21), 5312-5317 (2009).

Moraes, C.C., Mazutti, M.A., Maugeri, F. and Kalil, S.J., Modeling of Ion Exchange Expandedbed Chromatography for the Purification of C-phycocyanin, Journal of Chromatography A, 1281, 73-78 (2013).

Moraes, C.C., Ores, J.D., Costa, J.A.V. and Kalil, S.J., Recovery of C-phycocyanin in the Presence of Cells Using Expanded Bed IEC, Chromatographia, 74(3-4), 307-312(2011).

Moraes, C.C., Sala, L., Ores, J.D., Braga, A.R.C., Costa, J.A.V. and Kalil, S.J., Expanded and
Fixed Bed Ion Exchange Chromatography for the Recovery of C-Phycocyanin in a Single Step by Using Lysed Cells, Canadian Journal of Chemical Engineering, 93(1), 111-115 (2015).

Muller, A., Chaufer, B., Merin, U. and Daufin, G., Purification of $\alpha$-lactalbumin from a Prepurified Acid Whey: Ultrafiltration or Precipitation, Lait, 83(6), 439-451 (2003).

Myers, R.H., Montgomery, D.C. and AndersonCook, C.M., Response Surface Methodology: Process and Product Optimization Using Designed Experiments. Wiley (2009).

Oi, V.T., Glazer, A.N. and Stryer, L. Fluorescent phycobiliprotein conjugates for analyses of cells and molecules. J Cell Biol, 93(3), 981-986 (1982).

Patel, A., Mishra, S., Pawar, R. and Ghosh, P.K., Purification and characterization of C-Phycocyanin from cyanobacterial species of marine and freshwater habitat. Protein Expression and Purification, 40(2), 248-255 (2005).

Persistance, M.R., Global Market Study on Biopharmaceuticals: Asia to Witness Highest Growth by 2020. (2015).

Pignolet, O., Jubeau, S., Vaca-Garcia, C. and Michaud, P., Highly Valuable Microalgae: Biochemical and Topological Aspects, Journal of Industrial Microbiology \& Biotechnology, 40, (8), 781 (2013).

Prasad, K., Downstream Process Technology: A New Horizon In Biotechnology. Prentice-Hall Of India Pvt. Limited, New Dehli, (2012).

Pumas, C., Vacharapiyasophon, P., Peerapornpisal, Y., Leelapornpisid, P., Boonchum, W., Ishii, M. and Khanongnuch, C., Thermostablility of phycobiliproteins and antioxidant activity from four thermotolerant cyanobacteria. Phycological Research, 59(3), 166-174 (2011).

Ramos, A., Acien, F.G., Fernandez-Sevilla, J.M., Gonzalez, C.V. and Bermejo, R., Large-scale isolation and purification of C-phycocyanin from the cyanobacteria Anabaena marina using expanded bed adsorption chromatography. Journal of Chemical Technology and Biotechnology, 85(6), 783-792 (2010).

Reddy, M.C., Subliashini, J., Mahipal, S.V.K., Bhat, V.B., Reddy, P.S., Kiranmai, G., Madyastha, K.M. and Reddanna, P., C-Phycocyanin, a selective cyclooxygenase-2 inhibitor, induces apoptosis in lipopolysaccharide-stimulated RAW 264.7 macrophages. Biochemical and Biophysical 
Research Communications, 304(2), 385-392 (2003).

Rimbau, V., Camins, A., Romay, C., Gonzalez, R. and Pallas, M., Protective effects of C-phycocyanin against kainic acid-induced neuronal damage in rat hippocampus. Neuroscience Letters, 276(2), 75-78 (1999).

Rito-Palomares, M., Nunez, L. and Amador, D., Practical application of aqueous two-phase systems for the development of a prototype process for c-phycocyanin recovery from Spirulina maxima. Journal of Chemical Technology and Biotechnology, 76(12), 1273-1280 (2001).

Sarada, R., Pillai, M.G. and Ravishankar, G.A. Phycocyanin from Spirulina $\mathrm{sp}$ : influence of processing of biomass on phycocyanin yield, analysis of efficacy of extraction methods and stability studies on phycocyanin. Process Biochemistry, 34(8), 795-801 (1999).

Scheer, H. and Kufer, W., Studies on Plant BilePigments .4. Conformational Studies on C-Phycocyanin from Spirulina-Platensis. Zeitschrift Fur Naturforschung C-a Journal of Biosciences, 32(7-8), 513-519(1977).

Silva, L.A., Kuhn, K.R., Moraes, C.C., Burkert, C.A.V. and Kalil, S.J., Experimental Design As A Tool For Optimization Of C-Phycocyanin Purification By Precipitation from Spirulina platensis. Journal of the Brazilian Chemical Society, 20, 5-12 (2009).

Silveira, S.T., Quines, L.K.D.M., Burkert, C.A.V. and Kalil, S.J., Separation of Phycocyanin from Spirulina platensis Using ion Exchange Chromatography. Bioprocess and Biosystems Engineering, 31(5), 477-482 (2008).

Singh, N.K., Parmar, A. and Madamwar, D., Optimization Of Medium Components For
Increased Production Of C-Phycocyanin From Phormidiumceylanicum and its Purification By Single Step Process. Bioresource Technology, 100(4), 1663-1669 (2009).

Song, W., Zhao, C. and Wang, S., A Large-Scale Preparation Method OfHigh Purity C-Phycocyanin. International Journal of Bioscience, Biochemistry and Bioinformatics, 3(4), 293-297 (2013).

Soni, B., Kalavadia, B., Trivedi, U. and Madamwar, D., Extraction, Purification And Characterization Of Phycocyanin from Oscillatoria quadripunctulataIsolated From The Rocky Shores of Bet-Dwarka, Gujarat, India. Process Biochemistry, 41(9), 20172023 (2006).

Sørensen, L., Hantke, A. and Eriksen, N.T. Purification of the photosynthetic pigment C-phycocyanin from heterotrophic Galdieria sulphuraria. Journal of the Science of Food and Agriculture, 93(12), 29332938 (2013).

Szalontai, B., Gombos, Z., Csizmadia, V. and Lutz, M., The chromophore structure and chromophoreprotein interactions in C-phycocyanin as studied by resonance Raman spectroscopy. Biochimica et Biophysica Acta (BBA) - Bioenergetics, 893(2), 296-304 (1987).

Vincent-Vela, M.C., Cuartas-Uribe, B., AlvarezBlanco, S. and Lora-Garcia, J., Analysis of an Ultrafiltration Model: Influence of Operational Conditions. Desalination, 284, 14-21 (2012).

Vonshak, A., 2002. Spirulina Platensis Arthrospira: Physiology, Cell-Biology and Biotechnology. Taylor \& Francis.

Wheelwright, S.M., The Design of Downstream Processes for Large-Scale Protein Purification. Journal of Biotechnology, 11(2-3), 89-102(1989). 